\title{
Work from Home (Wfh) Arrangements During Covid-19 Pandemic: Comparative Analysis of Practices Among the Universities in Negara Brunei Darussalam Hajah Nur Annisa Haji Sarbini
}

\author{
Lecturer
}

Faculty of Islamic Economics and Finance

Universiti Islam Sultan Sharif Ali (UNISSA)

Email: nurannisa.sarbini@unissa.edu.bn

\section{Brunei \\ Professor Dr Razali Mat Zin}

Professor

Faculty of Islamic Economics and Finance

Universiti Islam Sultan Sharif Ali (UNISSA)

Email: razali.matzin@unissa.edu.bn

\section{ABSTRACT}

\section{Brunei}

Currently, all countries in the world are shocked by a global pandemic called Corona Virus Disease (COVID-19). This virus attack has had a huge impact on humans in the world and has changed many important aspects of life such as health, economy, politics, and also security. We have seen how COVID-19 has become a major threat to all organizations in the world, which has led to changes in work methods and also human interaction within the organization. The working method shifting in question is a change in the organization in giving tasks and responsibilities to its employees by "prohibiting" its employees to work in the office and gather in a room. This prohibition is not intended to destroy the performance of the organization but rather aims to prevent the spread of COVID-19, which until now continues to add the number of its victims globally. The concept of Work from Home (WFH) has been the subject of discussion and global study theme by researchers in the past 10 years, but this global phenomenon begins to emerge at the coming of the COVID-19 attack and becomes an alternative strategy for many organizations. However, in Brunei, this Working from Home (WFH) initiative or arrangement has not been widely implemented yet and become a work culture in the organization, although there are still a few organizations that have given the flexible arrangement of work for their employees. WFH, which is a phenomenon today in Brunei, is not a work culture found in many organizations, especially government organizations that are very bound by direct supervision, discipline, and also public services. In reality, WFH is not fully understood by the employees, they feel a lot of dilemma conditions such as the mindset that the home is where they rest while work is generally done in the office. This dilemma condition sometimes creates conflicts within the family even though WFH creates flexibility of time and place. Therefore, this paper tries to excavate and compare the different WFH arrangements that have been executed by three higher education institutions in Brunei following the de-escalation plans that have been widely disseminated by the government during the active spread of COVID-19. The findings suggest that different institutions have different ways of interpreting and implementing the WFH arrangements. This paper concludes with preliminary suggestions on managerial perspectives and implementation of flexible working arrangements like WFH and further research to be done in tackling the perceptual attitudes of employees undergoing the WFH initiative.

\section{Keywords: Work-From-Home, COVID-19, WFH, flexible arrangements}

\section{INTRODUCTION}

In the global arena, the Covid-19 virus attack has had tremendous ramifications on human life in the world and has altered the way we conduct our daily routines. Not only that, the virus has become a major threat to all organizations in the world, which has led to changes in work methods and also human interaction within the organization. Organizations are forced to find alternative ways to handle the impacts of the pandemic on their productivity while at the same time trying to maintain and sustain their activities with the new normal.
There has also been a shift in the working method whereby organizations need to come up with ways to distribute tasks and responsibilities to their employees by 'prohibiting' their employees to come to work in the office and gather in a room. This prohibition is not intended to destroy the performance of the organization but rather aims to prevent the spread of COVID-19, which until now continues to add the number of its victims globally. In light of that, since the official declaration of the COVID-19 spread as an international pandemic by the World Health Organization (WHO) on the 11th of March 
2020, the Government of Brunei Darussalam and several companies had adopted the Work from Home (WFH)" option for numerous jobs to activate social distancing and race with time in combating the local spread of the virus. This situation presents a large-scale experiment, and a field of research opportunity to understand the notion of WFH from diverse perspectives.

The concept of Work from Home (WFH) has been the focal point of academic discussion and political maneuvering in almost all countries in the world. As mentioned previously, Brunei is not familiar with the notion of WFH as there has never been a need to consider this alternative or arrangements amongst the employees, especially in the public sectors, although there are still a few organizations that have given the flexibility arrangement of work for their employees most of these organizations are private organizations. As mentioned previously, WFH is not a work culture found in many organizations in Brunei, especially government organizations that are very bound by direct supervision, discipline, and also public services. In reality, WFH is not fully understood by the employees, they feel a lot of dilemma conditions such as the mindset that the home is where they rest while work is generally done in the office. This dilemma sometimes creates conflicts within the family even though WFH creates flexibility of time and place. From this thought, the paper aims to excavate and compare the different WFH arrangements that have been executed by three higher education institutions in Brunei following the de-escalation plans that have been widely disseminated by the government during the active spread of COVID-19.

\section{LITERATURE REVIEW}

The Covid-19 pandemic has affected the work system of the organization globally. Mustajab et al (2020) stated that when doing work from home, many employees feel a balance in carrying out their work and social life. The idea of Work from Home (WFH) is a conceptualization process whereby a person can carry out the work responsibilities assigned to him in the comfort of his or her own home. The notion of WFH derives from a flexible alternative that organizations have adopted before the Covid-19 pandemic, whereby flexihours and remote working are common terms that were used, implemented, and catered especially for specific working groups such as women and mothers. Reddy and Ramasamy (2018) indicate that work from home provides flexibility in working. Indeed, WFH is beneficial for maintaining a balance between work and life and at the same time benefiting the organization whereby the employees are still able to complete their work at home. Due to the pandemic, organizations globally are turning to offer their respective employees with WFH option. Descriptive evidence suggested that WFH was on a growth trend before the beginning of the pandemic. Research in the United Kingdom showed that starting in 2006, the number of workers working from home has increased by $20 \%$ (Felstead \&
Henseke, 2017). Baruch (2003) stated that by working from home, employees can gain freedom of access to certain jobs, through less distraction from the office and more communication time and accessibility to communicate virtually.

Currently, WFH is a strategy adopted by many organizations throughout the globe. WFH provides benefits for many organizations where many expenses can be cut such as rent for office buildings, employee mess, and other work support facilities that must be prepared by the employer. International Labour Office (ILO) reported that there are multiple benefits associated with WFH, including the reduction in commuting times; greater autonomy and flexibility in the organization of work; a better work-life balance; increased motivation and reduced turnover; and enhanced productivity and efficiency. In addition, reduced travel associated with WFH leads to a reduction in carbon emissions (ILO, 2020).

One advantage of the WFH arrangement is that it could increase motivation with reduced stress among the employees while at the same time could benefit the organization whereby cost could be reduced due to the decreased usage of organizational facilities. The idea of WFH is where employees working from home can do office work as well as tasks needed to be done at home simultaneously. In 2015, an experiment was conducted on a large Chinese travel agency company with 16,000 employees, in which a group of call center employees was chosen to WFH for nine months on a self-selection basis. Results showed that working from home resulted in a $13 \%$ performance increase in productivity; displayed by the increase of minutes worked per shift, the higher number of calls taken per minute, and fewer breaks and sick leaves. This was attributed to improved work conditions at home such as quietness and convenience. In addition, homeworkers reported improved work satisfaction, and their retention rate doubled (Bloom et al., 2015). Shafizadeh et al. (2000) also claim that working from home increases the productivity of the employees.

In another study, Thorstensson (2020) analyzed five research articles published in the year 2000 and another five published in years 2019 and 2020 to discover the factors influencing the productivity of the employees who work from home. They also established the finding that working from home influences the productivity of the employees. While the influences of some of the factors are either positive or negative, the influence of some of the factors depends on the characteristics and attitude of the employees and the circumstances.

In Germany, Alipour et al. (2020) conducted the same assessment using the Employment Survey 2018. A rough estimate showed that $56 \%$ of jobs in the economy can be performed from home. Considerable variability by industry is also confirmed, where the percentage reaches $86 \%$ for the 
financial sector. A similar study showed that $36 \%$ of total jobs in the Norwegian economy can be performed at home (Holgersen et al., 2020). In Malaysia, data suggests that workfrom-home is possible for less than $30 \%$ of all workers due to the arrangement being suitable for high-skill jobs only (Tumin, 2020). The percentage falls sharply in developing countries; an analysis conducted using World Bank's STEP survey indicated that a very small share of workers may feasibly carry out their jobs from home reaching 6\% in Ghana (Saltiel, 2020).

One positive impact that can contribute greatly to increasing employee morale at work is when employees can find a balance in using their time to do work and non-work activities. However, with the implementation of the WFH initiative, it could lead to a negative impact on the performance of the employees themselves where employees who work at home spend more time or do not have a proportional percentage of their time in carrying out family and work responsibilities (De Tiroina and Sulaiman, 2021).

As indicated above, WFH has both benefits and drawbacks for the employees when it is compared to working in the office. One negative impact of WFH as disclosed by Dua and Hyronimus (2020) indicates that WFH has an influence on work-life balance, whereby it can cause conflict between work life and non-work interests, such as family.

In Brunei, this Work from Home (WFH) arrangement has not become a work culture in the organization, there are still a few organizations that have given the flexibility to work for their employees. Since WFH is not a work culture found in most organizations in Brunei, especially government sectors that are very bound by direct supervision, discipline, and also bureaucracy. However, due to the pressing nature of the pandemic, organizations in Brunei need to adapt to the changes in the working arrangement by offering an alternative solution to WFH. According to Saraceni (2020), the concept of alternative work arrangements represents a growing trend within many organizations to shift once-common models of working to newer paradigms. Among many options, this includes models where employees may work from somewhere other than a primary physical office space (remote work), or no longer possess a personal desk at their office (desk sharing). Both remote work and desk sharing often require employees to adapt to a mode of "working" far different than they are accustomed to, yielding a range of conflicting opinions, pros and cons, and unique experiences along the way.

In reality, WFH is not fully understood by the employees, they feel a lot of dilemma conditions such as the mindset that the home is where they rest while work is generally done in the office. This dilemma condition sometimes creates conflicts within the family even though WFH creates flexibility of time and place, see (McCloskey, 2018). However, WFH has shortcomings such as the lack of performance as a team and also the system of supervision that is not maximal by the manager, (Lippe, 2019), but besides having its lacks, the study results have also shown that WFH provides flexibility and discretion for employees to do their works without being supervised directly by supervisors or managers (Kossek, 2015).

When looking from the perspectives of employers, WFH could also be interpreted differently by the organizations, which could result in a different way of handling the WFH arrangements. Thus, it is clear that WFH is a strategy for many organizations with all the advantages and disadvantages that must be received by both the organization and its employees. Flexibility, trust, life balance between work, social, and losses that must be received such as lack of trust, additional costs, and also multitasking of employees who are certainly different in gender is an interesting phenomenon to be studied so that the development of the WFH concept becomes wider and contributes to increasing the productivity of human resources work in organizations, see (Krasulja, Vasiljevic-Blagojevic, \& Radojevic, 2015).

\section{METHODOLOGY}

This study is qualitative exploratory research adopting the document analysis methodology by reviewing the Work from Home (WFH) documentations provided and disseminated by the organizations to their respective employees.

Document analysis is a form of qualitative research in which documents are interpreted by the researcher to give voice and meaning around an assessment topic (Bowen, 2009). Analyzing documents incorporates coding content into themes similar to how focus group or interview transcripts are analyzed (Bowen, 2009). There are three primary types of documents (O’Leary, 2014):

a. Public Records: The official, ongoing records of an organization's activities. Examples include student transcripts, mission statements, annual reports, policy manuals, student handbooks, strategic plans, and syllabi.

b. Personal Documents: First-person accounts of an individual's actions, experiences, and beliefs. Examples include calendars, e-mails, scrapbooks, blogs, Facebook posts, duty logs, incident reports, reflections/journals, and newspapers.

c. Physical Evidence: Physical objects found within the study setting (often called artifacts). Examples include flyers, posters, agendas, handbooks, and training materials.

For this study, we decided to focus our document analysis on the public records which include the policy guidelines of all three universities, namely Universiti Brunei Darussalam (UBD), Universiti Islam Sultan Sharif Ali (UNISSA), and Universiti Teknologi Brunei (UTB). For UBD, the document entitled "UBD Guidelines on Staggered Work Attendance (Work From Home)". For UNISSA, the document entitled "Interim Guidelines for COVID-19 Prevention Measures at Sultan Sharif Ali Islamic University" and 
wwW.cpernet.org

"Kehadiran Bekerja Secara Berperingkat (BSBP)". For UTB, they put the memorandum and information on their website under the tag 'Covid-19' which is accessible for everyone.

Document analysis is a social research method and is an important research tool in its own right, and is an invaluable part of most schemes of triangulation, the combination of methodologies in the study of the same phenomenon. To seek convergence and corroboration, qualitative researchers usually use at least two resources through using different data sources and methods (O'Leary, 2014). The purpose of triangulating is to provide a confluence of evidence that breeds credibility. Corroborating findings across data sets can reduce the impact of potential bias by examining information collected through different methods. Also, combining qualitative and quantitative sometimes included in document analysis called mixed-methods studies.

\section{SIGNIFICANCE OF THE STUDY}

The significance of this study aims to explore the way different organizations interpret and implement the WFH arrangements based on the circular being distributed by the higher authority, in the case of this research, is the Prime Minister's Office. To do so, it involves making the comparison between the three local universities (organizations), namely Universiti Brunei Darussalam (UBD), Universiti Islam Sultan Sharif Ali (UNISSA), and Universiti Teknologi Brunei (UBD), and how they implemented and conducted the WFH arrangements during the high peak of Covid-19 situation in Brunei last year, 2020. The reason why we need to compare these three universities is that there is a difference in interpretation of the circular that was provided by the Prime Minister's Office about WFH arrangements.

\section{ANALYSIS OF FINDINGS}

Based on the analysis of the three documentation sources obtained from the three universities, we have decided to compare in terms of similarities and differences between the WFH arrangements and options that were made available for their respective employees. Below are the similarities and differences that were found in all relevant documents provided and obtained from the three universities.

\subsection{Similarities}

a. All three universities specify that WFH is not leaving. This can be found in all three documentations that were disseminated to their respective employees:

"Kindly note that working from home does not equate to a free day" (UBD)

"Work from Home (WFH) will be considered on a case by case basis with the approval of the Rector. The opportunity to WFH is not eligibility and can only take place through a formal agreement between the University and the Staff. Generally, the cases that can be considered are related to the health of the officer/staff or other reasons that the University deems reasonable." (UNISSA)
"Please be informed that WFH is NOT CONSIDERED AS A LEAVE." (UTB)

b. All three universities indicated that the WFH time is the same as office time, which is $\mathbf{7 . 4 5}$ am to $\mathbf{1 2 . 1 5}$ am and $\mathbf{1 . 3 0}$ pm to $4.30 \mathrm{pm}$ :

"The normal working hours still apply to those who are working from home, i.e. $7.45 \mathrm{am}-12.15 \mathrm{pm}$ and 1.30 pm-4.30 pm." (UBD)

"Eligible employees who are supported by their respective Heads/Deans/Directors and allowed/approved by the Rector to undergo BSBP, i.e. either working in the office (on-campus) in the MORNING and work at home in the AFTERNOON only or vice versa where both working times are according to the working hours indicated, which is 7.45 am to $12.15 \mathrm{pm}$ and $1.30 \mathrm{pm}$ to $4.30 \mathrm{pm}$." (UNISSA)

"WFH means performing work outside campus following the normal working hours that is from 7.45 am to $12.15 \mathrm{pm}$ and $1.30 \mathrm{pm}$ to $4.30 \mathrm{pm}$." (UTB)

c. All three universities used the term 'vulnerable staff' and identified the list of vulnerability in the same manner and description as indicated by the Ministry of Health:

"Staff who are vulnerable, with the following conditions, can be given special consideration to WFH. Should the staff opted to voluntarily not taking the WFH option, staff should observe the preventive health measures prescribed by the Ministry of Health:

- Pregnant

- Have pre-existing or high-risk medical conditions such as diabetes, cardiovascular diseases, respiratory illnesses such as asthma and cancer

Elderly (aged 60 and above)" (UBD)

"This consideration is subject to the following criteria:

3. Vulnerable staff such as having diabetes, high blood pressure, hypertension, cancer, and other chronic diseases including pregnant mothers and citizens aged 60 years and above." (UNISSA)

"Staff who fall under the following categories and have declared their medical condition to the respective Assistant Registrar / Head of Section are considered as vulnerable staff and they can be given special consideration to WFH daily.

(a) 60 years old and above

(b) Having underlying medical conditions e.g. respiratory illness, cardiovascular disease, hypertension, diabetes, kidney disease, and cancer; and

(c) Expecting mothers" (UTB)

d. All three universities specified that not all staff are eligible to apply for WFH:

"Not all staff are eligible, supervisors will need to assess the eligibility based on the criteria mentioned in the guideline." (UBD) 


\section{(C) Center for Promoting Education and Research (CPER) USA}

wwW.cpernet.org

"Suspension of Academic Activities at UNISSA Campus from Saturday 14th March 2020 to Saturday 28th March 2020 - all academic staff, officers, and support staff are required to report for duty as usual, although teaching and learning have commenced virtually... UNISSA is considering ALL CITIZEN (both academic and non-academic) to Bekerja Secara Berperingkat (BSBP)." (UNISSA)

"As an additional measure to minimize the risk of potential COVID-19 spread in the workplace, the University also allows non-vulnerable staff to WFH but on rotation. The rotation will be on a week-by-week basis except for certain jobs that require some staff to be on campus daily, where halfday shifts could be considered." (UTB)

e. All three universities required that the WFH applications must be officially approved before the commencement of WFH. Although there are differences in the mechanisms applied for approval from these universities and will be discussed in the differences further below:

"Selection of staff who are eligible to WFH would be at the consideration and assessment of direct supervisor of staff, e.g. depending on roles and duties of the staff and how crucial the duties of the staff is.. approved by the direct supervisor." (UBD)

"Work from Home (WFH) will be considered on a case by case basis with the approval of the Rector. The opportunity to WFH is not eligibility and can only take place through a formal agreement between the University and the Staff. Generally, the cases that can be considered are related to the health of the officer/staff or other reasons that the University deems reasonable." (UNISSA)

"It is the responsibility of the respective Programme Leader/line manager to schedule the rotation in consultation with the staff members. The recommendation from the Programme Leader/line manager should be approved by the respective Dean/Director/Head of Section endorsed by the Vice-Chancellor." (UTB)

f. Both UBD and UNISSA also indicated the needs for their staff to keep a record of the work activities done during WFH:

"All staff who are assigned to WFH, they are required to maintain accurate and up-to-date records of hours worked. Head of Departments are required to review and sign-off on records of hours worked." (UBD)

"All officers and staff undergoing WFH must record tasks performed during the WFH period and state the results of tasks performed or otherwise (output)" (UNISSA)

g. All three universities started to disseminate the WFH arrangement information about the same time after Brunei was hit with its first Covid-19 contact on March 15th, 2020, which was between $17^{\text {th }}-25^{\text {th }}$ March 2020:
"Emails were sent to all staff (both academic and nonacademic) by the Assistant Registrar via the Registrar's Office on 17th March 2020." (UBD)

"Circular was disseminated to all staff and students on 17th March 2020. Suspension of Academic Activities at UNISSA Campus from Saturday 14th March 2020 to Saturday 28th March 2020 - all academic staff, officers, and support staff are required to report for duty as usual, although teaching and learning have commenced virtually." (UNISSA) "All avenues. Via email, website and IG. BCP for WFH was disseminated on 25 March 2020." (UTB)

\subsection{Differences}

a. For differences between the three universities, we found that UTB allows non-vulnerable staff to WFH but on a week-by-week rotation basis, while UBD and UNISSA considered the Staggered Attendance Work Mode and Bekerja Secara Beperingkat (BSBP) respectively. This means that staff who WFH can work on campus for one half of the working day, either in the morning or in the afternoon, and spend the other half working off-campus:

"As an additional measure to minimize the risk of potential COVID-19 spread in the workplace, the University also allows non-vulnerable staff to WFH but on rotation. The rotation will be on a week-by-week basis except for certain jobs that require some staff to be on campus daily, where halfday shifts could be considered." (UTB)

"Staggered Attendance Work Mode: "Consideration for staff to work from home can be given to eligible staff in a staggered manner, in which staff can work on campus for one half of the working day (either in the morning OR in the afternoon), while the other half can be spent working offcampus." (UBD)

"Eligible staff will be supported by their respective Heads/Deans/Directors and approved by the Rector to undergo BSBP, i.e. either work in the office (on-campus) in the MORNING only and work at home in the EVENING only or vice versa and according to the normal working office hours." (UNISSA)

b. There is also a difference in the mechanism adopted by the three universities in the approval process and procedures for WFH, whereby for UBD there is no involvement of the Vice-Chancellor as the delegation of decision making on staff's eligibility to WFH is solely done and executed by the respective Direct supervisors. For UTB however, they indicated that it is the responsibility of the respective Programme Leader or Line Manager to schedule the rotation in consultation with their staff members, and the recommendation from the Programme Leader or Line Manager should be approved by the respective Dean or Director or Head of Section and endorsed by the Vice-Chancellor. Meanwhile, for UNISSA, there was an establishment of the UNISSA Task Force with the Rector as the Chairman and some of the executive 
committee and principal officers selected as the members. UNISSA also appointed its Acting Registrar as the focal point for its Business Continuity Plan (BCP):

"Selection of staff who are eligible to WFH would be at the consideration and assessment of direct supervisor of staff, e.g. depending on roles and duties of the staff and how crucial the duties of the staff is... final decision of staff's eligibility to WFH is their respective direct supervisor." (UBD)

"It is the responsibility of the respective Programme Leader/line manager to schedule the rotation in consultation with the staff members. The recommendation from the Programme Leader/line manager should be approved by the respective Dean/Director/ Head of Section endorsed by the Vice-Chancellor. Program Leader/Line Manager arranges rotation schedules for staff on a week-by-week basis in consultation with the staff members and should be approved by the respective Dean/Director/Head of Section, endorsed by the VC." (UTB)

"UNISSA is considering ALL CITIZEN (both academic and non-academic) to Bekerja Secara Berperingkat $(B S B P)$. Eligible staff will be supported by their respective Deans or Directors or Heads of Section and approved by the Rector to undergo BSBP and WFH." (UNISSA)

c. Of the three universities who adopted the WFH arrangement, we found that UNISSA was the only university that required the staff who underwent WFH to do 'Roll Call' which is a specified time during the working hours for the staff to 'report' or 'register' to their respective dean or director. This 'Roll Call' has to be done at $8 \mathrm{am}, 12$ noon, and $3 \mathrm{pm}$ every day that the staff was undergoing WFH:

"Staff who BSBP must register with their respective Heads at the ROLL CALL time set at 8.00 am (for the morning shift) and $3.00 \mathrm{pm}$ (for the afternoon shift) by keeping the registration record for future reference. The Head shall sign the record for verification. For staff undergoing WFH, the ROLL CALL must register to their respective Heads of Department for 3 times, which are at $8.00 \mathrm{am}, 12.00$ noon and 3.00 pm." (UNISSA)

d. Other differences between the three universities are in terms of who can apply for WFH. We found that UTB mentioned in their information to their staff that nonvulnerable staff can apply for WFH but on a week-by-week rotation basis, while UBD indicated that all staff (both vulnerable and non-vulnerable) can apply for WFH depending on the assessment of their direct supervisor. However, for UNISSA, it was specified that non-vulnerable staff cannot apply for WFH:

"Staff who fall under the following categories and have declared their medical condition to the respective Assistant Registrar / Head of Section are considered as vulnerable staff and they can be given special consideration to
WFH daily. For non-vulnerable staff, the University also allows WFH but on rotation. The rotation will be on a weekby-week basis except for certain jobs that require some staff to be on campus daily, where half-day shifts could be considered." (UTB)

"Not all staff are eligible, supervisors will need to assess the eligibility based on the criteria mentioned in the guideline. Vulnerable staff can be given special consideration to work from home entirely, if possible. Both academic and non-academic staff. Selection of staff who are eligible to WFH would be at the consideration and assessment of direct supervisor of staff, e.g. depending on roles and duties of the staff and how crucial the duties of the staff is." (UBD)

"UNISSA is considering ALL CITIZEN (both academic and non-academic) to Bekerja Secara Berperingkat $(B S B P)$ whereby from Home (WFH) will be considered on a case-by-case basis with the approval of the Rector. The opportunity to WFH is not eligibility and can only take place through a formal agreement between the University and the Staff. Eligible staff must be supported by their respective deans or directors and approved by the Rector" (UNISSA)

\section{DISCUSSIONS OF FINDINGS}

Based on the findings above, we found that there are different interpretations and implementation guidelines of the WFH arrangement between the three universities. Although they received the same circular from the Prime Minister's Office, when it comes down to putting it into action and implementing the WFH arrangements, the three universities proved to apply the WFH arrangement differently from one another. Based on the differences of this implementation, we found that the decision for WFH arrangements trickled down to their respective employees have also impacted differently to those who were involved and those who were not involved. In their zeal to implement WFH, the top management of three universities in Brunei must always remember that that working from home and meetings by Zoom have undeniable benefits along with serious drawbacks. Many empirical shreds of evidence suggest strongly that flexible schedules, more family time, and cost savings on commuting have been a blessing for some employees, but trying to work while kids are remoteschooling, the monotony of virtual meetings, and the absence of personal interactions have proved exhausting for others.

In UNISSA, for example, the final approval for an employee to go on WFH must go to the highest hierarchy i.e. the Rector. This requirement imparts a lack of flexibility, often leads to inefficiency, and causes unnecessary long delays. The immediate Supervisor (as practiced by UBD) should be granted the authority since they know the readiness and abilities of their staff much better than the highest-level leader who is far detached from the concerned employees.

From the guidelines, each university is not providing a clear design of WFH for their employees in terms of logistical and administrative preparation. Without proper preparation for 
the adoption of WFH, both leadership and staff are missing the opportunity to design, understand, and agree to the terms of a WFH. This makes responsibilities unclear and can create an unhealthy environment full of assumptions and unmet expectations. Some relevant significant questions such as (i) How will performance and accessibility standards change? (ii) Who will be responsible for home office expenses? How often do employees still need to come to the office, if ever? (only UBD did mention that the WFH staff can work on campus for half of the working day, while the other half can be spent working off-campus. (iii) Will the employees who chose to WFH be discriminated against those who continue working in the office. All these questions pose a further action or research that could be explored to understand how the pandemic has impacted an organization's most valuable asset its Human Resources.

\section{RECOMMENDATIONS}

Based on these findings and discussions, we suggest some managerial recommendations for implementing WFH arrangements amongst public sectors and higher education institutions. These recommendations are:

1. The Brunei Public Service Department should revisit the policy guidelines for WFH. They should provide clear guidelines so that all higher educations in Brunei Darussalam would implement their respective WFH arrangements uniformly. Any discrepancies among each institution would create confusion and dissatisfaction among the employees who are involved in WFH initiatives.

2. Organizations including higher education institutions in Brunei that introduce a WFH program should create specific guidelines to ensure all employees understand what is required from them when they work remotely. One of the key elements involved have the proper arrangement is for the management to ensure that the employees involved have the proper technology and infrastructure such as computer, email, phone conferencing, access to internal networks are all tools that they need.
3. Higher education institutions in Brunei must implement communications strategies that allow the top management and supervisors to stay in touch with employees who work from home via Zoom, Google Teams, Skype, Slack, and other messaging services. In many sectors, the findings showed that at times, remote employees can feel isolated from the rest of the non-WFH colleagues. Thus, supervisors need to keep in contact with them via phone, email, messaging, or video conferences.

4. One of the most crucial elements of a work from home arrangement is not included in the actual document. Employers need to have trust in their employees to get their jobs done when they are not working onsite. For example, the requirement to report for duty by UNISSA where the WFH employees need to call (roll call) their respective immediate supervisor three times a day should be re-evaluated.

5. The management of higher education institutions in Brunei needs to be aware that WFH can pose a cybersecurity risk. If an employee is not using a secured Wi-Fi or VPN, their computer could be open to a cyber-attack. Employees should also be aware of the physical security of their electronic devices. The top management must ensure that WFH employees keep their laptops to themselves and securely store them in safe-keeping when they are not in use.

For future research, since WFH has become the alternative for some employees in Brunei higher education institutions, policymakers need to conduct studies periodically to establish some empirical findings of the impacts of this arrangement on employees. As one of the most business factors for organizations is the productivity of their employees, it is important to find out whether WFH has a negative and/or positive influence on productivity. We could also suggest for future research to interview the employees or staff who were involved with WFH and those who were not involved with WFH for their perception, experiences, and perspectives of WFH and no-WFH and understand the impacts and effects of WFH on their health, work-life balance and well-being.

\section{REFERENCES}

Alipour, Falck, Schüller (2020) “Germany's Capacities to Work-from-home” CESifo Working Papers, ISSN 2364-1428 (electronic version)

Baruch, Y. (2003). The status of research on teleworking and an agenda for future research. International Journal of Management Reviews, 3(2), 113-129. https://doi.org/https://doi.org/10.1111/1468-2370.00058

Bloom, N., Liang, J., Roberts, J., \& Ying, Z. J. (2015). Does Working from Home Work? Evidence from a Chinese Experiment. The Quarterly Journal of Economics, 130(1), 165-218. https://doi.org/10.1093/qje/qju032

Bloom, N., Liang, J., Roberts, J., \& Ying, Z. J. (2015). Does working from home work? Evidence from a Chinese experiment. The Quarterly Journal of Economics, 130(1), 165-218.

Bowen, G. A. (2009). Document analysis as a qualitative research method. Qualitative Research Journal, 9(2), 27-40. doi:10.3316/QRJ0902027 
De Tiroina, S., and Sulaiman M. (2021), The Effect of Work From Home During The Covid-19 Pandemic on Work-Life Balance and Its Impact on Employees Performance of Aceh Communication, Informatics and Encoding Office, International Journal of Business Management and Economic Review, Vol. 4(2), ISSN: 2581-4664

Dua, M. H. C., \& Hyronimus. (2020). Pengaruh Work From Home Terhadap Work-Life Balance Pekerja Perempuan Di Kota Ende. Jurnal Ilmiah Manajemen Bisnis Dan Inovasi Universitas Sam Ratulangi, 7(2), 247-258. https://doi.org/https://doi.org/10.35794/jmbi.v7i2.30266

Felstead, A., and Henseke, G. (2017). Assessing the growth of remote working and its consequences for effort, well-being and work-life balance, New Technology, Work and Employment, Vol 32(3), pp 195 - 212. https://doi.org/10.1111/ntwe.12097

Holgersen, H., Jia, Z., \& Svenkerud, S. (2020). Who and How Many Can Work-from-home? Evidence from Task Descriptions and Norwegian Job Advertisements. Evidence from Task Descriptions and Norwegian Job Advertisements. Modern Press: Norway.

Kossek et al (2015), Balanced Workplace Flexibility: Avoiding the Traps, California Management Review, Vol 54(4), pp 5-25. DOI:10.1525/cmr.2015.57.4.5

Krasulja, N., Blagojevic, M. V., \& Radojevic, I. (2015). Working from home as alternative for acheving work-life balance. Ekonomika, 61(2), 131-142. https://doi.org/10.5937/ekonomika1502131K

Lippe, TVD (2019), Co-workers working from home and individual and team performance. New Technology, Work and Employment, Vol 35(1), pp 60-79

McCloskey, D. W. (2018). An examination of the boundary between work and home for knowledge workers. International Journal of Human Capital and Information Technology Professionals, 9(3), 25-41. https://doi.org/10.4018/IJHCITP.2018070102

Mustajab, D., Bauw, A., Rasyid, A., Irawan, A., Akbar, M. A., \& Hamid, M. A. (2020). Working From Home Phenomenon as an Effort to Prevent COVID-19 Attacks and Its Impact on Work Productivity. The International Journal of Applied Business, 4(1), 13-21. https://doi.org/http://dx.doi.org/10.20473/tijab.V4.I1.2020.13-21

O'Leary, Z. (2014). The essential guide to doing your research project (2nd ed.). Thousand Oaks, CA: SAGE Publications, Inc.

Reddy, L. S., \& Ramasamy, K. (2018). introspection Of Work-From- Home In It Industry. International Journal of Advance and Innovative Research, 5(4), 522-535.

Reddy, L. S., \& Ramasamy, K. (2018). introspection Of Work-From- Home In It Industry. International Journal of Advance and Innovative Research, 5(4), 522-535.

Reddy, L. S., \& Ramasamy, K. (2018). introspection Of Work-From- Home In It Industry. International Journal of Advance and Innovative Research, 5(4), 522-535.

Saltiel, F. (2020). Who can work-from-home in developing countries? Covid Economics, 7(2020), 104-118.

Saraceni, N., Kent, P., Ng., L., Campbell, A., Straker, L., and O'Sullivan, P. (2020), To Flex or Not to Flex? Is There a Relationship Between Limbar Spine Flexion During Lifting and Low Back Pain? A Systematic Review With Metaanalysis, J Orthop Sports Phys Ther, Vol 50(3), pp 121-130. doi: 10.2519/jospt.2020.9218

Shafizadeh, KR., Mokhtarian, PL., Niemeier, D., Salomon, I. (2000). The Costs and Benefits of Home-Based Telecommuting, https://www.researchgate.net/publication/46439032_The_Costs_and_Benefits_of_Home-Based_Telecommuting

Thorstensson, E. (2020). The Influence of Working from Home on Employees' Productivity Comparative document analysis between the years: 2002; 2019-2020. Karlstad Business School.

Tumin (2020) "How common is working from home?" DISCUSSION PAPER 4/2020. Khazanah Research Institute.

Uddin, M. (2021), Addressing work-life balance challenges of working women during COVID-19 in Bangladesh, International Social Science Journal, Volume 71, Issue 239-240, John Wiley \& Sons Ltd. DOI: https://doi.org/10.1111/ISSJ.12267 